\title{
Investigation of a case of prednisolone malabsorption
}

\author{
T. G. K. MANT \\ B.Sc. \\ Clinical Pharmacology Department, Guy's Hospital Medical School, London SEI 9RT
}

\begin{abstract}
Summary
Malabsorption of prednisolone administered as enteric coated tablets was suspected following therapeutic failure in an asthmatic. This was investigated by cortisol estimation and a Synacthen test and substantiated by the demonstration of abnormally low absorption of prednisolone from these tablets which nevertheless were normally absorbed by a volunteer. The absorption of prednisolone from conventional tablets in this patient was normal.
\end{abstract}

\section{Introduction}

It has been suggested that the use of enteric coated prednisolone in place of standard oral prednisolone preparations may be associated with a lower risk of peptic ulceration and aggravation of pre-existing peptic ulcers (West, 1959). The bioavailability of enteric coated prednisolone and non-enteric coated prednisolone is not significantly different in normal subjects (Morrison, Bradbrook and Rogers, 1977). This communication reports a case of abnormal absorption of enteric coated prednisolone in a patient who absorbed non-enteric coated prednisolone normally and the use of cortisol estimations and prednisolone plasma levels in the investigation of poor clinical response to prednisolone.

\section{Case report}

A 50-year-old female hospital receptionist, was admitted to hospital complaining of severe breathlessness attributed to 'extrinsic' asthma. Her medication before admission was conventional prednisolone $15 \mathrm{mg} /$ day which she had taken for 2 months, salbutamol inhaler 2 puffs 4 times daily, beclomethasone dipropionate inhaler $100 \mu \mathrm{g} 4$ times daily, ampicillin $500 \mathrm{mg} 3$ times daily and Asilone.* The latter was given for dyspepsia, a duodenal ulcer having been diagnosed on barium meal examination 12 years previously. On admission she received intravenous hydrocortisone and, after $12 \mathrm{hr}, 60 \mathrm{mg}$ oral prednisolone followed by $45 \mathrm{mg}$ oral prednisolone daily. In view of her history of peptic ulceration she was

\footnotetext{
* Dimethicone $250 \mathrm{mg}$, aluminium hydroxide $500 \mathrm{mg}$, sorbitol $500 \mathrm{mg}$, per tablet (Berk Pharmaceuticals).
}

given this as an enteric coated preparation of prednisolone.

This change to oral steroid therapy was not accompanied by the expected clinical improvement or any of the normal side effects associated with steroid therapy.

\section{Investigations and results}

To investigate possible prednisolone malabsorption basal cortisol levels were measured and a Synacthen stimulation test was carried out on the twentieth day after admission. These showed low basal levels $(90,95,110 \mathrm{nmol} / \mathrm{l})$ and an impaired response $(11.00 \mathrm{hr}, 110 ; 12.10 \mathrm{hr}, 205 ; 12.55 \mathrm{hr}, 480$ $\mathrm{nmol} / \mathrm{l} ; 2 \mathrm{mg}$ Synacthen given i.m. at $11.45 \mathrm{hr}$ ) but not the more complete suppression to be anticipated following prednisolone therapy (Shenfield et al., 1974). These results suggested impaired absorption.

To confirm this clinical impression plasma prednisolone levels were estimated by a fluorescent, thin layer chromatographic technique developed in the Clinical Pharmacology Department at Guy's Hospital (Morrison et al., 1977). Plasma prednisolone levels were measured in this patient following 45-mg enteric coated prednisolone and one day later following $45 \mathrm{mg}$ non-enteric coated prednisolone (Fig. 1). Plasma prednisolone levels were also measured in a normal volunteer following 10-mg enteric coated prednisolone (Fig. 1). The enteric coated tablets used for both subjects were from the same batch (Deltacortril, ${ }^{\circledR}$ Pfizer).

Figure 1 shows that in the normal volunteer there is a delay (lag time) before prednisolone is detectable in the plasma as might be expected following the enteric coated preparation. Both preparations produced similar peak levels. These results are consistent with previous data on plasma prednisolone levels in normal subjects (Morrison et al., 1977). The patient has no lag time and a low peak level following the enteric coated prednisolone compared to the nonenteric coated preparation. It was concluded that the patient absorbed prednisolone from enteric coated formulations poorly. She subsequently received 20 mg standard oral prednisolone daily with gradual 


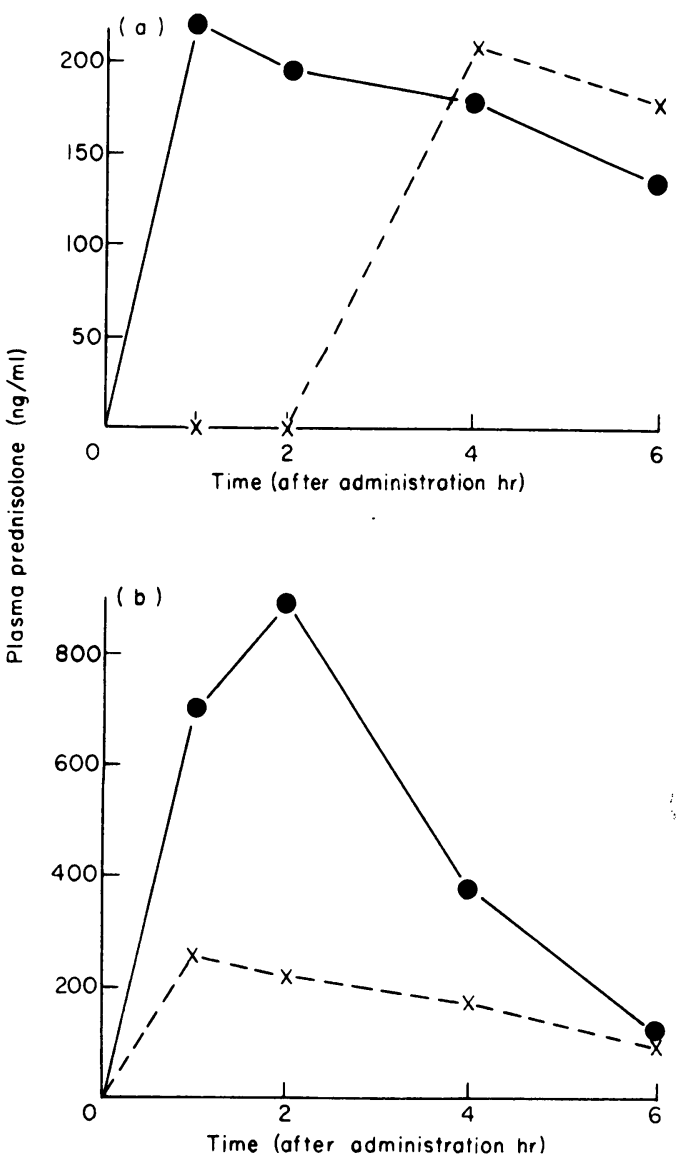

FIg. 1. Plasma prednisolone levels in the patient (b) following oral administration of $45 \mathrm{mg}$ prednisolone as conventional (- - $)$ and enteric coated $(x \ldots x)$ tablets and in a volunteer (a) following $10 \mathrm{mg}$ prednisolone as conventional (C-O) and enteric coated $(x-. \times)$ tablets from the same batches.

improvement in clinical response and she was discharged 42 days after admission.

\section{Discussion}

This case illustrates the necessity for awareness of possible drug malabsorption. The poor clinical response to prednisolone suggested poor prednisolone absorption. The incomplete cortisol suppression supported this clinical impression. The use of a pred- nisolone assay indicated impaired bioavailability following the enteric coated preparation but normal bioavailability following the standard oral preparation.

The cause of the enteric coated prednisolone malabsorption in this case remains obscure. As tablets from the same batch showed normal bioavailability in a normal volunteer a batch fault in formulation is unlikely. The patient was concurrently taking Asilone, terbutaline, effervescent potassium, frusemide, penicillin $\mathrm{V}$ and amoxycillin. The first 3 drugs together with the stress of her illness would be expected to decrease the gastric-emptying rate causing a delay in peak level but duodenal ulceration is associated with an increased gastric-emptying rate (Nimmo, 1976). Possibly concurrent administration of Asilone may have sufficiently increased gastric $\mathrm{pH}$ to allow slow leakage of prednisolone through the enteric coat thus making the drug available for absorption and thus hepatic first pass metabolism. Malabsorption syndromes can affect drug absorption (Parsons, 1977) byt this patient had no symptoms suggestive of a malabsorption and her daily faecal fat measured over 3 days was $0.4 \mathrm{mmol}$ (normal range $<18 \mathrm{mmol}$ ).

Although the cause of the malabsorption of the enteric coated prednisolone is unknown in this patient the enteric coated preparation showede biological inequivalence to the conventional ora preparation. This was confirmed by a basal cortiso: level of $45 \mathrm{nmol} / \mathrm{l}$ and the development of Cushingoid features when enteric coated prednisolone therapy was replaced by conventional tablets and the dose reduced from $20 \mathrm{mg} /$ day to $2.5 \mathrm{mg} /$ day after discharge.

\section{References}

Morrison, P.J., Bradbrook, I.D. \& Rogers, H.J. (1977) Plasma prednisolone levels from enteric and non-enteric coated tablets estimated by an original technique. British Journal of Clinical Pharmacology, 4, 597.

Nimmo, W.S. (1976) Drugs, diseases and altered gastric emptying. Clinical Pharmacokinetics, 1, 189.

Parsons, R.L. (1977) Drug absorption in gastrointestinal disease with particular reference to malabsorption syndromes. Clinical Pharmacokinetics, 2, 45.

Shenfield, G.M., Paterson, J.W., Costello, J.F. \& IJadVALA, O. (1974) The effect of prednisolone treatment on the half-life of intravenous cortisol. British Journal of Clinical Pharmacology, 1, 237.

WEST, H.J. (1959) Prevention of peptic ulceration during corticosteroid therapy. British Medical Journal, 1, 680. 